\title{
ARRACADA ORIENTALIZANTE DE VILLANUEVA DE LA VERA (CÁCERES): PROPUESTA DE RECONSTRUCCIÓN
}

\author{
ORIENTALISING PENDANT EARRING FROM VILLANUEVA DE LA \\ VERA (CÁCERES). A PROPOSAL FOR ITS RECONSTRUCTION
}

\author{
por
}

\author{
$M^{\mathrm{a}}$ LUISA DE LA BANDERA ROMERO
}

\begin{abstract}
RESUMEN Se presenta una propuesta de identificación de unos fragmentos de orfebrería de Villanueva de la Vera y la posible reconstrucción de su forma como arracada. Se llega a esta conclusión al contrastar la estructura formal y temática de los fragmentos y las arracadas orientalizantes conocidas. También se exponen algunas consideraciones sobre el origen y las relaciones de las arracadas orientalizantes.
\end{abstract}

\begin{abstract}
A proposal is made here to identify some fragments of jewelry from Villanueva de la Vera and their possible reconstruction as a pendandt earring. We have arrived at this conclusion after having contrasted the formal structures and decorative themes of the orientalizing pedant earrings that are known. Some considerations are expounded about the origin and the relations of orientalizing pendant earrings.
\end{abstract}

\section{INTRODUCCIÓN}

En el año 1992, con motivo de la Expo 92 celebrada en Sevilla, admiré en el Pabellón de Extremadura un bello fragmento de orfebrería que llamó poderosamente mi atención no sólo por su estilo orientalizante sino por estar clasificado como "diadema". En aquel momento, y de la simple observación a través del cristal de la vitrina, intuí que se trataba muy posiblemente de una parte de arracada orientalizante. La pieza en cuestión procedía de Villanueva de la Vera (Cáceres) y, junto con otras, fue hallada casualmente en la Cañada de Pajares con la remoción de las tierras para las labores agrícolas, durante varios años. 
Poco después en 1993, realizadas las oportunas diligencias ${ }^{1}$, pude hacer un estudio directo de los fragmentos, los cuales habían sido depositados en el Museo Provincial de Cáceres tras su adquisición en 1989 por la Consejería de Educación y Cultura de la Junta de Extremadura. Sin embargo los resultados no se hicieron públicos entonces, porque tuvimos noticias de la existencia de otros fragmentos similares, procedentes del mismo entorno entre el Arroyo Boguillas y la Cañada de Pajares, depositados en el Ayuntamiento de Villanueva de la Vera los cuales estaban siendo estudiados por otros investigadores ${ }^{2}$; así que decidimos esperar su publicación y también los resultados de las intervenciones arqueológicas que se realizaban en la Cañada de Pajares. El lote de los primeros hallazgos, las circunstancias de su hallazgo, así como un estudio y análisis arqueométrico, se dieron a conocer en una primera publicación (González y otros, 1993), y un estudio más reciente de las piezas, en relación con otros de la zona, se encuentra en prensa cuando realizamos este artículo (Blanco y Celestino, 1998 :e.p.).

Hoy, analizando y contrastando algunos estudios y publicaciones recientes sobre la orfebrería orientalizante en la Península Ibérica y mi propia investigación sobre la de Pajares (Villanueva de la Vera, Cáceres), quiero presentar una propuesta de identificación de los fragmentos como elementos de arracadas orientalizantes “de doble suspensión y aureola perimetral" (Bandera 1987:83,281 ss.; 1989:47-51). La propuesta y reconstrucción que aquí se expone no es un resultado aislado, fruto únicamente del análisis de la orfebrería de Villanueva de la Vera conservada en el Museo Provincial de Cáceres, sino la manifestación de las continuas reflexiones a las que someto la contrastación de hipótesis ya expuestas sobre la producción de orfebrería (Bandera 1987; 1984:364-418) y de bronces orientalizantes de la Península Ibérica: su tecnología, los talleres, y su valor social (economía, representatividad, simbología), (Bandera 1994).

En la actualidad los planteamientos del estudio de la orfebrería en general son encauzados dentro de una perspectiva de la complejidad social. Se intenta desvelar a través de ella por una parte el nivel de desarrollo tecnológico, y en relación a éste el poder éconómico de esa sociedad y sus centros de producción; y por otra parte escudriñar su valor social y en cierto modo ideológico por medio de la temática. Esta tendencia no es "nueva" pues ya en algunos trabajos de orfebrería de la última década se destacaba la importancia de la joyería como fuente de información histórica y no sólo como documento artístico (Bandera 1984:366), en los cuales además se manifestaba la necesidad de realizar análisis físico- químicos más específicos que contrarestasen aquellas tecnologías que eran propuestas desde un estudio morfológico y de análisis en relación con la temática y el estilo de las corrientes culturales de los períodos estudiados (Bandera 1987: 712-734; 1989: 25-30). Esa perspectiva de estudio proporcionó unos presupuestos hipotéticos que, aunque no se complementaron con análisis de laboratorio (causa por la cual algunos investigadores pretenden ignorarlos), sin embargo las más recientes investigaciones sobre tecnología de producción de la orfebrería peninsular, los está confirmando (Montero y Rovira 1991:11; Perea 1991; Rovira 1995; Perea y Armbruster 1998).

Por ello, en el estado actual de la investigación de la orfebrería, tengo el convencimiento de que no se pueden minusvalorar los aspectos formales y estilísticos frente a los tecnológicos, sino que tienen que ser valorados en una igualdad porcentual, puesto que es la conjunción de todos ellos -tecnología, formato y temática- la que puede llegar a determinar una fecha de elaboración, fases evolutivas, o taller. La determinación, en cambio, del período de uso de un objeto de orfebrería es más compleja y está condicionada por dos factores: uno físico debido a la materia prima, el oro (producto amortizable como riqueza); y otro social en cuanto que su producción es utilizada para representar estamentos sociales-religiosos (pervivencia por herencia) o bien ideologías. Y como para llegar a una información más completa se necesita un amplio

1. Agradecemos a $D^{a}$. Pilar Caldera la ayuda que me prestara para acceder a su estudio, así como a la Consejería de Cultura de la Junta de Extremadura y a la directora del Museo de Cáceres haberlo podido realizar

2. La información nos fue suministrada por el Dr. S. Celestino Rodríguez, quién tuvo la gentileza de facilitarnos unas fotos de las mismas con las cuales pudimos completar nuestro estudio. 
“corpus" de objetos bien identificados y analizados (Rovira 1995: 494,nota 4), creo que nuestra aportación puede ayudar a tal fin.

En esta línea la región extremeña es de una riqueza extraordinaria en orfebrería y toreaútica para el Bronce Final y el Período Orientalizante. La producción de metales juega un papel importante para investigar los procesos de cambio y desarrollo determinantes de cada período, si se parte de la consideración que los cambios son detectables en los objetos metálicos a partir de las técnicas, formatos e iconografía específicas utilizadas; presupuesto que no sólo es válido para esta región sino para todo el Suroeste peninsular. Sin embargo el Período Orientalizante en Extremadura aún sigue planteando serios problemas de interpretación socio-cultural, ya que contrasta ampliamente la riqueza de objetos hallados con la carencia de contextos arqueológicos conocidos, tanto para la propia orfebrería como para el período en general. Y por ello los importantes lotes de orfebrería, estelas, bronces, etc., hallados en su espacio, han sido y siguen siendo una base para determinar los rasgos culturales diferenciadores, aunque algunos autores consideran que con la orfebrería no es posible concretar cronologías ni delimitar áreas o grupos, y que a lo más que podemos llegar es únicamente a señalar grandes bloques estilísticos de producción (Celestino 1995: 75,67).

Por otra parte, el estudio de la orfebrería plantea otra problemática acerca de la existencia y localización de los talleres de producción (Rovira 1995: 486-487). La existencia de talleres locales de orfebrería y metalistería orientalizante en Extremadura ha sido propuesta y admitida por muchos investigadores como se desprende de la extensa bibliografía sobre el tema (Almagro 1977, 1989; Bandera 1987; 1994: 432-434; Nicolini 1990: 624; Perea 1991: 201, 202; Fernández Gómez 1996: 14), pero se mantienen distintas posturas interpretativas en cuanto al factor humano: para unos son orientales cedidos a las élites (Almagro 1990), para otros los productos son introducidos desde el "hinterland" gaditano en una primera fase, siendo clara una fase más reciente de producción indígena con asimilación de lo oriental (Nicolini 1990; Celestino, 1991; 1995: 74; Olmos 1992: 41). Desde nuestra perspectiva el proceso de aparición de talleres locales -a nivel regional o zonal en Extremadura y en todo el Suroeste- va relacionado con el proceso de evolución hacia una estructura compleja de la sociedad que afecta al área, siendo más bien una cuestión de crecimiento numérico. Se detecta pues, en los cambios tecnológicos que se producen en el Bronce Final al contacto con las colonias, un artesanado especializado de origen oriental (Bandera 1987:714-715) que se establecería no sólo en las colonias sino probablemente en zonas próximas a los centros de transformación de los metales o minas, y que entra en contacto con la población indígena, como ocurre en el S. VIII a.C. en el Egeo y el Mediterráneo (Coldstream 1982: 274), y que trabajando al amparo de reyezuelos locales, en centros religiosos, o a nivel doméstico, sería la base de aparición de otro artesanado plural (orientales, indígenas, mestizos) más o menos identificado unilateralmente con la tradición oriental y/o con la indígena. Estos artesanos, herederos de técnicas precoloniales de tradición atlántica y aprendices de las innovaciones orientales y mediterráneas desarrollarían esa producción "orientalizante" de gran eclecticismo en la orfebrería característica de la primera mitad del s. VI a.C. (Bandera 1984: 366, 377, 387-91; 1987: 758-759; Perea y Armbruster 1998), y con rasgo diferenciadores en los bronces (Bandera y Ferrer, 1994a: 54-56; 1994b; 1995), en respuesta de esa población heterogénea que habitaría sobre todo los centros comerciales y nucleares del Suroeste y Sur peninsular (Alvar 1990: 17-19; Gasull 1993: 81-82; Belén y Escacena 1995: 94; Chaves y Bandera 1993: 71).

La orfebrería de Villanueva de la Vera ha sido incluida dentro de una producción diferenciada de la del Sur y Sureste denominada "unidad de producción de estilo sudoccidental", la cual abarcaría un vasto territorio desde Ebora (Sanlúcar de Barrameda, Cádiz) hasta Sines en Portugal, más todo el territorio extremeño (Celestino 1995: 74). Sin embargo opino que en este conjunto se incluyen objetos que, aunque son del mismo período orientalizante, corresponden a fases o talleres distintos, por lo cual es necesario hacer análisis metalográficos y contrastes más detallados de las relaciones entre técnicas de elaboración, formatos y temática iconográfica para diferenciarlos. 
Persiguiendo ese objetivo se ha realizado el análisis tecno-morfológico y estilístico de los fragmentos conservados en el Museo Provincial de Cáceres, su identificación y relación con las arracadas orientalizantes en un campo formal, tecnológico y temático; sin olvidar que de ese marco espacial procede un buen número de objetos de bronce orientalizantes.

\section{DESCRIPCIÓN}

El conjunto lo componen fragmentos de una lámina acintada de oro con pequeñas piezas soldadas en una de sus caras, y otra serie de pequeñas piezas sueltas (González y otros 1993: 252, lám. I). El estado tan deteriorado y fragmentado de lo que se conserva ha obligado a presentar un dibujo técnico de las partes que lo estructuran, señalando en él las medidas para el mejor entendimiento de las descripciones y de los argumentos en los que basamos la reconstrucción (fig. 1:1).

Entre los distintos fragmentos se documentan dos partes de una lámina-A y B-de desiguales dimensiones, las cuales presentan por un extremo una linea de fractura y por el otro la punta redondeada correspondiente a cada uno de los límites que componía el cuerpo completo. El mayor de ellos (A) mide 10'62 cm. de largo y el menor (B) 6'40 cm., siendo el ancho de ambas de 1'06 cm. y el grosor de 0'01 cm. (lám. I y II).

En el anverso de la lámina -considerada así porque sería la parte visible de la misma- se destaca una decoración de motivos astrales en resalte dentro de un campo de fino granulado, cuyas medidas oscilan entre $0^{\prime} 7 \mathrm{~mm}$. y $2^{\prime} 5 \mathrm{~mm}$., quedando la composición delimitada por tres alambres: dos hilillos lisos con uno central torseado. Los motivos astrales son dos series de crecientes: en una de ellos el creciente abraza el disco solar y se dispone por parejas contrapuestas en el sentido longitudinal de la lámina, mientras la otra serie, sin disco solar, se dispone igualmente por parejas, pero encarados entre sí, en los espacios intermedios de los anteriores en sentido trasversal. En las zonas donde coinciden los extremos de dos crecientes, uno vertical con otro longitudinal, se marcan en relieve elementos petaliformes (lám. III). Entre las dos láminas se contabilizan actualmente 21 pares de crecientes con disco (dos pares sólo están iniciados en los bordes de la rotura).

El reverso de las láminas es liso. En él se conservan todavía algunas pequeñas piezas cónicas laminares de $5 \mathrm{~mm}$. de alto y $515 \mathrm{~mm}$. de diámetro, parcial o totalmente soldadas por la base, agrupadas en conjuntos de cuatro y dispuestas dos a dos en sentido trasversal de la cinta, como remate de florescencias de lotos abiertos (láms. I y II). Hemos contabilizado entre los dos fragmentos 51 conos (flores); 32 en el mayor y 19 en el más pequeño. Los conos están agrupados de cuatro en cuatro por una laminilla de $2 \mathrm{~mm}$. de ancho, troquelada con una hilera de perlado en el centro y dos finos boceles en los bordes, que actúa como abrazadera (fig. 1:1a). El extremo adelgazado de cada uno de los conos se marca con un hilillo sogueado, para diferenciarlo de la abrazadera. En el fragmento $B$ se comprueba que esta cinta troquelada servía para asegurar el enlace entre las flores y otro cuerpo inferior, por las dos muestras completas soldadas todavía a ellos (lám. II). En ellas se ve como las piezas acampanadas emergen, dos a dos, de cada una de las volutas de una palmeta de cuenco con un eje central (de 4'5 mm. de alto), que a su vez apoya en otra palmeta cerrada de botón central (de 5'5 mm. de alto). Esta segunda palmeta inferior descansa, a su vez, sobre una base cilíndrica de $1 ' 5 \mathrm{~mm}$., rodeada por una espiral de fino hilillo, que está delimitada por dos hilos lisos, perfilándose una especie de cuenta a imitación de las de jaulilla (lám. VI; fig.1:1a). Las dobles palmetas lucen un borde perlado, troquelado, en el interior de ambas y circulillos rehundido en las volutas. También troquelado es el perlado que luce el eje central que, saliendo de la palmeta de cuenco con botón central, se inserta en la cintilla abrazadera para reforzar el remate lotiforme. Aunque en el fragmento A no se ha conservado ningún elemento de este tipo, sí hay restos de un eje que emerge, a través de la abrazadera, del centro de un conjunto de cuatro conos. Además se conservan varios fragmentos sueltos correspondientes a tres de estos elementos, 
uno de ellos con una flor, y aparte dos flores sueltas (láms. VI, VIII). La altura del conjunto floral es de $1^{\prime} 9$ a $2^{\prime} 00 \mathrm{~cm}$.

En el extremo redondeado de la lámina del fragmento B se mantiene aún soldado parte de un elemento antropomorfo, que hacía de límite del adorno (lám. II), y en el del A también quedan restos de la pieza similar del lado contrario (lám. IV y V), la cual se conserva desprendida (lám. VII). Completando los restos aún adheridos al fragmento $B$ (parte de cabecita) con la pieza suelta del fragmento $A$, se ha podido determinar su forma y dimensiones. Se trata de un cuerpo único, hueco, en el que se han determinado varias partes como si se tratara de una columnilla, separadas unas de otras por diminutos baquetones horizontales (fig. 1:2). A manera de fuste hay un pedestalillo, cilíndrico (hoy algo aplastado) de $3^{\prime} 8 \mathrm{~mm}$. de diam. y $8 \mathrm{~mm}$. de alto, troquelado con aristas romas y marcadas con diminutos gránulos, que descansa sobre una esférula con umbo y círculo en resalte delimitado también con granulillos y punto al centro. Sobre él otro cuerpo, de perfil bitroncocónico, a manera de capitel de dobles volutas con una altura de $315 \mathrm{~mm}$., e igualmente delimitado por fino granulado, en parte totalmente perdido. Como remate una cabecita bifronte de $615 \mathrm{~mm}$ de alto, $6^{\prime} 5 \mathrm{~mm}$. de ancho y cuello de $3^{\prime} 8 \mathrm{~mm}$. ancho; igualmente con granulado para marcar el cabello a ambos lados de la cara y la base del cuello.

El peso total de lo conservado en el Museo de Cáceres es de 17'4 g. El fragmento A con 9'2 g, y el pequeño, $\mathrm{B}$, con $6^{\prime} 4 \mathrm{~g}$; la cabecita suelta con un peso de $0^{\prime} 4 \mathrm{~g}$ y el grupo de dos conjuntos de dobles flores con $0^{\prime} 6 \mathrm{~g}$.

\section{RECONSTRUCCIÓN DE LA PIEZA}

Los restos conservados se identificaron con dudas desde su hallazgo. En un principio se consideraron parte de diadema, y posteriormente se les denominaron "placas o arracada", rechazando esta última posibilidad, ante "la perfecta equidistancia entre las flores...que impiden una posterior curvatura" (González y otros 1993: 250 y 256). En las siguientes líneas se analiza el proceso mediante el cual se clasifican como parte de una arracada orientalizante de "aureola perimetral". Se llega a esta determinación tomando como base la conjunción de las técnicas empleadas, las medidas y temática representada.

\section{Técnica}

En todo el proceso de elaboración de lo conservado se han utilizado técnicas características del periodo orientalizante. La técnica de base fue laminar. El batido, estirado de hilos, y troqueles fueron los aplicados para dar forma a los distintos elementos que componen los fragmentos:

Conjunto de doble palmetas: se obtuvo a partir de dos láminas troqueladas y soldadas en su contorno, del mismo modo que los remates antropomorfos.

Cuerpos cónicos: se modelaron posiblemente sobre un molde (de piedra, cerámico, metálico) con la forma deseada y posteriormente se soldaron sobre las volutas de la palmeta superior por parejas. Estas piezas se completaron con distintas aplicaciones de hilos para ocultar la soldadura; unos, torneados, en la base de cada cono, y otros lisos en espiral rodeando el cilindro de la base de cada palmeta, formando una falsa cuenta de jaulilla.

Cintas abrazaderas: conseguidas por batido, y una vez cortadas, o antes, se repujaron el contario central y los boceles laterales, lo más probable mediante punzones de punta roma sobre molde.

Cinta perimetral: de las dos láminas, la externa se decoró con tres punzones distintos, creciente liso, creciente con disco solar y elemento de flora, antes de ser soldada a la de base. El perímetro se delimitó con tres hilos, uno sogueado entre dos lisos. 
Decoración: un fino granulado $\left(0^{\prime} 7 \mathrm{~mm}\right.$. a 2'5 mm.) es la técnica principal, mientras que la filigrana está escasamente representada. Con él se cubrió el campo de la cinta perimetral y también se delimitaron las siluetas y motivos interiores de los elementos antropomorfos. Un granulado debió cubrir también, en parte, los cuerpos de las dobles palmetas, pero no se conservan restos de ello. Esta decoración sería aplicada a toda la pieza en su fase última, una vez construida la arracada.

Soldadura: sistema utilizado para unir las distintas partes de los elementos sueltos, y estructurar la forma.

\section{Estructura formal y dimensiones (fig. 3: 2 y 3 )}

Son de distinta categoría los razonamientos contrastados que han conducido a esta proposición. Uno de ellos, al principio, fue puramente visual al observar detenidamente las alineaciones curvadas que aún conservaban las piezas cónicas despegadas de la lámina del fragmento A (lám. I) y las inclinaciones del grupo completo con doble palmeta del fragmento B (lám. II). Se planteó que el arco de circunferencia que en el fragmento A describían los tres grupos de florescencias del extremo conservado correspondían a parte de una aureola y que la lámina decorada delimitaba el perímetro máximo del arco de la circunferencia en el que se inscriben normalmente este tipo de arracada. A partir de esta hipótesis se procedió a determinar la longitud original de la lámina sobre la que soldaban las distintas piezas de conos y, de esta manera, cotejar con las dimensiones de las aureolas de arracada clasificadas del tipo I.

Se comenzó considerando primero los largos de ambas láminas: éstas suman $17^{\prime} 00 \mathrm{~cm}$.; pero si se analiza el dibujo del anverso, se contabilizan veinte (20) grupos de crecientes completos y los inicios de otro en cada extremo roto, lo que hace un total de veintidós (22) grupos. Como un grupo de crecientes mide 0 '92 $\mathrm{cm}$. (fig. 1c) obtenemos una longitud de $20^{\prime} 24 \mathrm{~cm}$. (22 x 0'92) que, teniendo en cuenta los extremos redondeados y lo arrugado de la lámina, podría oscilar entre $20^{\prime} 24$ y $20^{\prime} 50 \mathrm{~cm}$.

En segundo lugar, para contrastar esta longitud, se tomaron como referencia las piezas cónicas. Sobre las láminas se conservan aún 50 piezas cónicas, y una serie de espacios vacíos que son fácilmente contabilizables conociendo el diámetro de la base del cono (fig. 1a,b). Por una parte el fragmento más largo (lám. I) conserva ocho grupos de cuatro flores completos, más dos flores que son parte de otro grupo de 4 , y un hueco vacío para un grupo completo ( 4 conos); lo cual suma 40 conos (flores). Por otra, en el fragmento más corto (lám. II) se mantienen soldados cinco grupos de conos en el extremo ( 20 conos), seguido por un espacio libre con dimensiones para un grupo (4 conos); y en la zona de rotura otro grupo incompleto (4 conos). Así, se calculan unas sesenta y ocho flores de loto (68), repartidas en treinta y cuatro (34) parejas, formando 17 florescencias; a las que hay que añadir los dos prótomos antropomorfos. Por tanto, si se multiplica el total de piezas ( 34 conos +2 prótomos) por el diámetro de la base del cono $\left(0^{\prime} 56 \mathrm{~cm}\right.$. considerando una holgura de unión), se obtiene una longitud de $20^{\prime} 16 \mathrm{~cm}$. ( $36 \times 00^{\prime} 56 \mathrm{~cm}$.). Como podemos comprobar llegamos por las dos vías a un resultado similar, el cual se ha igualado en $20^{\prime} 20 \mathrm{~cm}$.

Hallada esta longitud de la aureola, el siguiente paso fue hallar el diámetro máximo probable, teniendo en cuenta que las arracadas orientalizantes Tipo I inscriben la decoración en una corona incompleta, dejando sin ocupar un tramo de la misma, de más o menos una quinta parte de la figura. Si se opera aplicando una ecuación de primer grado con una incógnita, y llamando " $X$ " a la longitud desconocida, tenemos que:

$$
4 / 5 X=20^{\prime} 20 ; \mathbf{X}=20^{\prime} 20 \times 5 / 4=25^{\prime} 25
$$

Luego la longitud de la circunferencia exterior sería de $25^{\prime} 25 \mathrm{~cm}$. A partir de este valor se determinó el diámetro máximo de la pieza: $25^{\prime} 25 \times 1 / 3^{\prime} 14=8^{\prime} 04 \mathrm{~cm}$., considerando finalmente para la reconstrucción un diámetro máximo probable de unos $8^{\prime} 00 \mathrm{~cm}$. Para el diámetro interior, tendríamos: $8^{\prime} 00-\left(2 \times 2{ }^{\prime} 00\right)=4^{\prime} 00 \mathrm{~cm}$. 


\section{Temática}

La serie de elementos decorativos aparecen dispuestos de una manera particular e intencionada, que se une muy claramente a toda una producción de objetos de fuerte carácter simbólico, entre los que destacan las joyas y las vajillas rituales, en cuyos esquemas vemos los mismos elementos: palmetas abiertas y cerradas, flores de loto, rosetas, y divinidades femeninas (fig. 4: 1 y 2) que se relacionan con la esfera mitológica. El esquema de la aureola, pues, puede interpretarse como una representación del "árbol de la vida" (González y otros 1994:256) protegido por la divinidad y la bóveda celeste.

Recopilando los resultados del análisis tecno-morfológico y temático se ha llegado a la propuesta, hecha supra, de reconstrucción (fig. 2: 3 y 2), en cuya explicación se sigue el proceso técnico probable de elaboración. Una vez obtenidos todos los elementos componentes (v. técnicas), la estructura de la arracada se habría realizado de la siguiente manera. De base habría un cuerpo central ultrasemicircular, amorcillado (fusiforme) de sección circular u oval (hecho de una o dos láminas), o bien una placa laminar, cuyos extremos disponían de algún sistema de enganche para el lóbulo de la oreja (fig. 2:2). En el perímetro exterior de este cuerpo se distribuyeron, de forma radial, diecisiete composiciones florales delimitadas por las cabecitas antropomorfas, bifrontes, sobre el capitel de un pedestal estriado. Por último la lámina acintada se extendió sobre las bases de los conos huecos, cerrando de esta manera el perímetro circular, y perfilando el cuerpo de la arracada. Posiblemente una pequeña cintilla conservada en uno de los bordes redondeados podría haber sostenido la anilla de enganche de la segunda suspensión (fig. 2:2).

\section{Ficha técnica}

— Arracada: Variante del tipo I (Bandera 1987;1989)

- Metal: Oro. Peso de lo conservado: 17'5 grm.; suponemos el $40 \%$ del total

— Dimensiones Arracada: diámetro máx. unos 8'00 cm.; aureola $20^{\prime} 20 \mathrm{~cm}$. de long.; 1'90 a 2'00 cm. de ancho.

— Técnicas: Modelado laminar. Troquelado. Cuerpos huecos independientes. Granulado. Hilos lisos, torsos y torneados. Soldadura.

— Temática: Guirnalda floral de palmetas y flores de loto. Cabezas antropomorfas sobre pedestalillos. Cubierta de símbolos astrales.

\section{ORIGEN Y RELACIONES}

En el conjunto de las arracadas orientalizantes, la pieza de Villanueva de la Vera pertenece a las de doble suspensión y aureola perimetral (Bandera 1987: tipo I; Nicolini 1990 "pendants d'oreille a croissant et couronne": 311-319; Perea 1991: Grupo 9, Tipo D; "fusiforme y crestería de flores": 151-153), tipo a partir del cual se desarrollaron otras series por añadidos de nuevos elementos (apéndices triangulares), o bien evolución de los primarios. Son pocos los ejemplares conocidos y todos ellos encajan en un marco espaciotemporal muy concreto: el Suroeste y Oeste peninsular desde fines del s. VII a.C. a mitad del s. VI a.C.

La homogeneidad de estas arracadas, cuyo pieza más representativa es el par de Aliseda (Cáceres) (fig. 3: 4b), se centra en las características técnicas y morfológicas. Todas son de oro; modeladas con troqueles y punzones; constan de elementos independientes y unidos por soldadura; y la mayoría luce decoración con granulado y filigrana. Sin embargo los sistemas de conformación, y los temas simbólicos representados en los adornos son determinantes de variantes. 
En las variantes, la morfología modifica su estructura en razón de las dimensiones, diferenciandose así dos grupos: las de Aliseda, Sines (Gaio) (García Bellido 1970: 25), y Villanueva de la Vera, con aureolas de $7^{\prime} 50 \mathrm{~cm}$ a $8^{\prime} 00 \mathrm{~cm}$ de diámetro máximo, $1^{\prime} 90 \mathrm{~cm}$ de ancho, y aproximadamente $20^{\prime} 00 \mathrm{~cm}$ de longitud; y las de Andalucía (antigua colección Vives, en el MAN), El Pedroso (Sevilla), Setefilla (Sevilla), y Baiao (Porto, Portugal), con diámetros máximos entre 4' $35 \mathrm{~cm}$ y 3'50 cm (Bandera 1987: 82-86, 284-303; 714-720). Por modificación del cuerpo central se determinan también dos variantes: las de aro alunado central abierto (fig. 3: 4a,b,c,d,f), y las cuatro arracadas de Baiao con cerramiento del espacio central por una lámina (fig. 3: 4e). Otra variante, por modificación en la estructura, se produce al "adaptar" la simbología a la decoración (Villanueva de la Vera).

Otra diferencia, que determina variantes dentro del tipo, es la que se produce en relación con los motivos decorativos, según la iconografía elegida para representarlos. Si se atiende a lo simbólico-religioso, unos lucen una iconografía interpretable como "árbol de la vida" y/o divinidad femenina relacionada con él; en tanto que otros son estilizaciones florales, solas o enmarcadas por cabecitas humanas. La variabilidad de lo simbólico no afecta a la estructura, más que en el ejemplar de Villanueva de la Vera, ya que en todas las arracadas se repite la misma simbología: la flor de loto, protegida por símbolos astrales (bóveda celeste), en una sacralización del mundo vegetal como atributo de una divinidad. Sin embargo, la manera de representarla origina variantes iconográficas las cuales pienso son indicio de factores entrecruzados correspondientes a dos niveles de la esfera social: uno puramente técnico, y otro mítico o religioso. En este caso las diferencias se reflejan en el soporte que sostiene la flor de loto, y en la manera de cubrirlas (fig. 4: 1a-d). En las de Aliseda y Andalucía, el soporte es una palmeta abierta de botón central; en las de Sines una cabecita hathórica; en Villanueva de la Vera una doble palmeta de cuenco, la misma que desarrollan las de Baiao. En cuanto a la cubierta, en Aliseda, Andalucía, y Sines es una rosácea independiente, en Villanueva un manto cuajado de crecientes, y ninguna en las restantes.

A nivel tecnológico, estas arracadas (tipo I), son creaciones locales a partir de las que se desarrollaron en el ámbito cultural de Asia Occidental y el Mediterráneo Oriental del s. IX al VII a.C. (Bandera 1987: 362ss); y aunque no se conocen unos prototipos claramente definidos, sí se destacan paralelos que hacen visible el origen oriental de su composición. Las relaciones más cercanas con los paralelos, se observan en la estructura y en el motivo decorativo más común a todas las peninsulares, como es la flor de loto. La estructura repite aquella de los grandes pendientes alunados, con colgantes de flores dispuestos en aureola, que son característicos de la producción de orfebrería asiria desde el s. IX-VII a.C. Una serie de pendientes, próximos a las arracadas de Aliseda (Fig. 3: 2 y 3), son representados en personajes de los paneles de caza de la época de Asurbanipal, y también los lucen el rey y su esposa en los relieves de Nínive (Parrot 1970: figs. 60, 65, 76). Este tipo de pendiente fechado no antes del s. VII a. C. (Maxwell 1971: tipo 5, 237, 242, fig. 127) es una forma evolucionada de un modelo anterior de apéndices cónicos, y que guarda cierta relación con las arracadas de Sines (Maxwell 1971: tipo 4, 240, fig. 133e-g). De esos pendientes de triple brazo, antecente del más complejo con aureola de flores (fig. 3:2 y 3) de los relieves, se conocen unos ejemplares de Tell Halaf (Maxwell 1971: 242, fig. 134), otros representados en relieves de Tiglatpiliser III, y en los paneles de Nimrud aparecen ejemplares porteados, como tributo o botín de guerra (Parrot 1970: 345), desde las tierras occidentales y meridionales por arameos, fenicios, etc. (Hulin 1963: 48). Sin duda todos ellos son una muestra de la producción desarrollada durante el dominio asirio, y que se expandió por todo el Mediterráneo dando lugar a tipos evolucionados. Un ejemplo excepcional es el pendiente de triple apéndice procente de Van, en el que se dan juntos los dos elementos más representativos de cada tipo asirio: apéndice con una guirnalda de palmetas desarrollada en su superficie, y roseta cubriendo la base (fig. 3: 1). Otras formas derivadas encontramos en ejemplares evolucionados en Efeso, Egina (Marshall 1969: 82; lams: X, 1068), Alepo, y en pintura de cerámica de Thera (Richter 1968: 25, lám. VIIIc). 
En la Península Ibérica, las arracadas de Aliseda y las de Sines adoptan las dos variantes de la producción asiria, de flores en apéndices y guirnaldas de palmetas y, aunque introducen elementos de estilo fenicioegiptizante como son el grupo heráldico de las palmetas con halcones y la cabecita hathórica (fig. 4:1a,1b), son la réplica más próxima a los prototipos asirios. En las restantes se desarrollan diferencias que las alejan de las orientales, determinando una posible evolución desde las peninsulares. Así la de Villanueva de la Vera modifica la estructura de soporte y de cubierta (Aliseda), y además incorpora la cabecita antropomorfa que la relaciona con las de Sines (fig. 4:1d). En las de menor tamaño, la de Andalucía (fig. 3:4d; y 4:1c) representa una continuidad evolucionada de la de Aliseda como Setefilla, mientras que la de El Pedroso comparte el formato de las anteriores, pero con abstracción de las flores, acercándola a las de Baiao, e introduce cabecitas humanas como Sines y Villanueva (fig. 3: 4e-f).

En cuanto al origen y relaciones de la iconografía nos encontramos que es de inspiración oriental, la cual en su lugar de origen tiene carácter simbólico y sagrado (Lagarce 1991: 556). El elemento común es la flor de loto, y su visible asociación con palmetas, rosetas, símbolos astrales, cabezas, sugieren cultos de fertilidad (Ishtar, Astarté, Artemis), signo de eternidad, o culto al sol, análogos a los que se producen en otros centros mediterráneos en torno al s. VII a.C. Así la iconografía de Aliseda de palmetas y rapaces se asocia al culto de Artemis, mientras las cabecitas de Sines con loto sobre ellas son relacionadas al culto solar. Por otra parte las palmetas abiertas asociadas a flor de loto tienen un origen chipriota, y el árbol de la vida de Aliseda se relaciona con creaciones propias del mundo asirio. Finalmente la iconografía de Aliseda y particularmente la de Sines (fig. 4: 1b) hay que ponerla en relación con la iconografía simbólica de objetos de bronces rituales en la Península. Un conjunto importante de estas piezas repite los mismos atributos que encontramos en la joyería. El timaterio de Estacar de Robarinas (Cástulo), y el de Villagarcía de la Torre (Badajoz)(fig. 4:2a-b) con una relación más cercana que el de El Raso (Candeleda, Ávila) o el de la Quéjola (San Pedro), con matizaciones estilísticas de corriente griega (fig. 4: 2c-d). La misma iconografía se repite en el Bronce Carriazo, y en las cabecitas de los braserillos de Carmona (Sevilla) o la Joya (Huelva). En toda, su iconografía se relaciona con la iconografía de Hathor desarrollada en la costa siria y en Chipre, donde cobra éxito con la conquista de la isla por el faraón Amasis en 570 a.C. (Bandera y Ferrer 1994b: 54).

En cuanto a la pieza de Villanueva de la Vera, la simbología se relaciona con florescencias de estilo chipriota en pintura de cerámicas, y en marfiles asirios con cronología de finales del s. VII a.C., aunque su elaboración pudiera ocupar el segundo cuarto del s. VI a. C. por la asociación de las cabecitas humanas con otra tipología. El tipo de Baiao, presenta una influencia del Mediterráneo Central en la palmeta de cuenco relacionada tanto con el mundo fenicio de Tharros, como con Etruria.

\section{CONSIDERACIONES FINALES}

La valoración de las variantes, y del grado de relación entre las mismas y su origen, me llevan a reflexionar sobre dos cuestiones: la producción, y la funcionalidad de las arracadas.

Desde un nivel tecnológico, la homogeneidad de formato y la pervivencia de las técnicas de elaboración contrasta con el número de las variantes que se producen en cuanto a la iconografía. A mi entender ello puede responder a la existencia de más de un taller. Y aunque intentar localizar los talleres, o distinguir orfebres, es aún tarea muy problemática, sí se pueden hacer ciertas reflexiones. Considero que en toda época los talleres, o centros de elaboración, se distinguen siempre por la producción de un determinado tipo, el cual repite al menos durante una generación, modificándolo o cambiándolo por una readaptación a nuevas tecnologías, o bien a la demanda de los grupos sociales. Si consideramos la producción del Suroeste, de finales 
del s. VII y s. VI a. C., en un mismo taller podrían haberse producido cuatro modelos de arracadas orientalizantes, pero relacionadas entre sí, de alguna manera.

Entre las arracadas del Suroeste se distingue una producción más temprana, con elementos cercanos a los de una producción oriental, y otras formas evolucionadas de las anteriores en las que se detectan las influencias. Así, las de Aliseda, Sines, y Villanueva corresponderían a una fase más temprana de este tipo de arracadas, con una cronología de principio del s. VI a.C. basada en los paralelos y la temática. Pero entre ellas se observan diferencias, en la iconografía simbólica, que sugieren no agruparlas a un mismo taller o artesano.

A una producción evolucionada, posiblemente de las de Aliseda se debería la de Andalucía y posiblemente la de Setefilla, mientras la de El Pedroso sería una creación a partir de las de Baiao, y adoptando cabecitas tanto de una tradición anterior (Sines), como etrusca. Observando las zonas de dispersión de estas arracadas y objetos de bronce con simbología relacionada (fig. 5), me inclino a pensar que la producción del tipo más arcaico, de doble suspensión y aureola, se desarrolla de manera sincrónica y paralela en distintos núcleos poblacionales, con actividad comercial y en centros religiosos, próximos a la costa de la vertiente atlántica, y hacia el interior de las vías fluviales del Guadiana, Guadalquivir, Tajo e incluso el Duero, y que dispondrían de un artesanado permanente. De las posteriores generaciones surgirían las formas evolucionadas de arracadas, como las arracadas de Marchena (Sevilla), Ebora (Sanlúcar, Cádiz), o Madrigadejo y otras extremeñas (Bandera 1987: 281-340). En ejemplar curioso, base de una evolución posterior es la pieza de Villanueva de Vera. En relación a la estructura laminar del perímetro, es posible que piezas similares fueran las emisoras de la corriente orientalizante tartésica llegada hasta la producción castreña, y a la que tanto han aludido los investigadores (Blanco 1957; Pérez Outeiriño 1982: 182-182). Quizás tengamos en esta arracada el eslabón que enlaza las arracadas castreñas con la producción orientalizante tartésica. Es curioso como la decoración de la arracada "abarquillada", del tesoro de Bedóia (fig. 3:4g) fue siempre identificada con "múscidos", o abejas estilizadas (Pérez Outeiriño 1982:92, fig. 25); cuando por mi parte creo reconocer una serie de palmetas en guirnalda, muy estilizadas, repitiendo el esquema de tradición orientalizante, pero con técnica distinta.

En cuanto a la funcionalidad de las arracadas, y solo en un breve planteamiento (Bandera 1999: e.p.), los elementos iconográficos asociados con divinidades orientales y sus atributos, las alejan de ser interpretadas como meros objetos de adorno. En algunas interpretaciones se plantea la posibilidad de que se trate de "una orfebrería funeraria", sin otro uso personal, por la fragilidad de las piezas y la ausencia de huella de uso (Nicolini 1990: 116). En otras, además de ésta, se propone un uso cultual solamente, como exorno de la imagen de la divinidad (Celestino 1995: 75). Creo que ambas interpretaciones no son excluyentes, sino acumulables, considerando la materia prima y la iconografía.

En relación exclusiva con estas arracadas se puede interpretar una múltiple funcionalidad: a) Por la materia prima y "costo" de su elaboración pueden ser objetos de prestigio, indicadores del estatus social y de privilegio del difunto. b) Por la iconografía simbólica pueden tratarse de "distintivo" de cargo, o servicio, vinculados con la Astarté fenicia, divinidad de la fertilidad y "enterradora" de Baal (Olmo 1991:367-372) siendo portados por sacerdotes/isas, o doncellas servidoras del templo, en vida o en la tumba. c) Como amuleto protector relacionado con la inmortalidad, igualmente vinculada la temática a una divinidad. Este valor representativo de carácter religioso lo encontramos recogido por la epigrafía oriental (Maxwell 1971: 1xi).

La valoración de algunas arracadas con esta funcionalidad de distintivo de servidores de Astarté se basa en los paralelos de las de Sines y la de Villanueva, con las cabecitas de "braseros", y con las cariátides de los timaterios de Robarinas (Cástulo) y de Villagarcía de la Torre (Badajoz) (fig. 4:2 a-b)

Considero, finalmente, que para una interpretación social de la producción de orfebrería orientalizante en la Península Ibérica, son muy escasos los soportes estratigráficos, y se necesitan más analíticas metalográficas, sin embargo he querido manifestar mis reflexiones para someterlas a las opiniones de mis colegas. 


\section{BIBLIOGRAFÍA}

ALMAGRO-GORBEA, M.(1977): El Bronce Final y el Periodo Orientalizante en Extremadura. Biblitheca Praehistorica Hispana, 14. Madrid.

(1989): "La Orfebrería Orientalizante. El oro en la España prerromana". Revista de Arqueología. Monografias. 68-51. Madrid.

__ (1990): "El Periodo Orientalizante en Extremadura". En La cultura tartésica y Extremadura. Mérida.

ALVAR, J. (1990): "El contacto intercultural en los proceso de cambio". Gerión 8, 11-27.

- (1991): "La religión como índice de aculturación: el caso de Tartessos". Atti del II Congresso di Studi Fenici e Punici I, 351-356.

BANDERA ROMERO, M.L. (1984): "Brazaletes peninsulares orientalizantes e ibéricos en metales nobles”. Habis $15 ; 365-418$. Sevilla.

_ (1987): La joyería orientalizante e Ibérica del s. VII al I a.C (Mitad Sur peninsular). Ed. microfichas. Sevilla.

- (1989): La joyería prerromana en la provincia de Sevilla. En Arte Hispalense. Diputación provincial de Sevilla. Sevilla.

(1994): "Técnica y sociedad prerromana". Arqueología en el entorno del Bajo Guadiana,415-439. Huelva.

- (e.p.): "Funcionalidad y simbología de la orfebrería tartésica". Habis, Sevilla.

BANDERA, M.L. y FERRER, E. (1994a): "Thymiateria orientalizantes en bronce. Nuevas aportaciones y consideraciones", en Sáenz, P. y Ordóñez, S. (eds.), Homenaje al Profesor Presedo, 43-60. Sevilla, Universidad de Sevilla.

- (1994b): "El thymiaterio orientalizante de Villagarcía de la Torre (Badajoz)", Archivo Español de Arqueología 67, 41-60. Madrid.

- (1995): "Reconstrucción del ajuar de una tumba de Cástulo: ¿indicios de mestizaje?”, Homenaje al Profr. Gascó, en Kolaios, 4, 53-65.

BELÉN, M. y ESCACENA, J.L. (1995): “Interacción fenicios-indígenas en el Bajo Guadalquivir”. Kolaios 4: $67-101$.

BLANCO FREJEIRO, A. (1965): "El ajuar de una tumba de Cástulo", Oretania 19.

- (1956): "Orientalia. Estudio de objetos fenicios y orientalizantes en la Península". AEspA. XXIX, pp. 3-51.

- (1957): "Origen y relaciones de la orfebrería castreña". Cuadernos de estudios Gallegos XII; 5-28.

BLANCO, J.L. y CELESTINO, S. (1998): "La joyería orientalizante peninsular: diversidad de particularidades". Complutum 9 (en prensa).

BLÁZQUEZ, J.M. (1963): “Las joyas orientalizantes extremeñas del Museo Arqueológico Nacional”. Zephyrus $X I V$.

BORDMAN, J: "The Archaeology of jewelry" en Calinescu, A. (ed.) Ancient Jewelry and Archaeology, 1996.

CALINESCU, A., (ed): Ancient Jelwelry and Archaeology. 1996.

CELESTINO, S.(1991): "Nuevos jarros de bronce en el Suroeste peninsular". Madrider Mitteilungēn, 32.

- (1995): "El Periodo Orientalizante en Extremadura". Extremadura Arqueológica IV, Arqueología en Extremadura: 10 años de descubrimientos, 67-90.

COLDSTREAM, J.M. (1982): "Greeks and phoenicians in the Aegean”. Phöenizie im Westem, Ed.: Niemieyer, H.G., Mainz.

CHAVES, F. y BANDERA, M.L. (1993): "Problemática de las cerámicas pintadas "orientalizantes" y su contexto". Actas V Coloquio de Lenguas y Culturas Paleohispánicas. Colonia 1989. pp. 49-89. Salamanca. 
CHAPA, T. y PEREIRA, J.(1991): "El oro como elemento de prestigio social en época ibérica". A.Esp.A. 64, 23-35.

FERNÁNDEZ GÓMEZ, F. (1996): "Joyas de oro en Castros de la Meseta: Ulaca y Raso de Candeleda". Numantia 6. Arqueología en Castilla y León.1993-1994, 9-30. Junta de Castilla y León. Valladolid. (1997): "Una tumba orientalizante en "El Raso de Candeleda" (Ávila): Alle soglie della classicitá. Il Mediterraneo tra tradizione e innovazione. Studi in honore di Sabatino Moscati, pp. 725-740. Roma GARCÍA BELLIDO, A. (1960): "Inventario de los jarros púnico-Tartéssicos", Archivo Español de Arqueología 33: 45-47. (el tesoro de Sines 23-28 fig. 2.)

GASSULL, P. (1993): "El sistema ritual fenicio: inhumación e incineración". $M M, 34 ; 71-82$.

GONZÁLEZ, A.; ALVARADO, M; BLANCO, J.L. (1993): "Las Joyas Orientalizantes de Villanueva de la Vera (Cáceres)", Trab. Preh. 50, 249-262.

GONZÁLEZ WAGNER, E.C. (1983): “Aproximación al proceso histórico de Tartessos”. AEspA 56, 3 ss. HULIN, P. (1963): "The inscriptions on the carved throne base of Shalmaneser III". Irak XXV, 1; pp. 48-65.

LAGARCE, E. (1991): "Le rôle d'Ugarit dans l'elaboration du repertoire iconographique syro- phenicien du premier millénaire avant J.C.". Atti del II Congresso Internazionale di Studi Fenici e PuniciI, 547-561. Roma.

MARSHALL, F.H. (1969): Catalogue of the Jewellery Greek, Etruscan, and Roman in the Departments of Antiquities, British Museum. Londres.

MAXWELL, K.R. (1971): Western Asiatic Jewellwry c. 3000-612 B.C. Methuen ed.; Londres.

MÉLIDA, J.R. (1921): Tesoro de La Aliseda. Madrid.

MONTERO, J. y ROVIRA, S. (1991): "El oro y sus aleaciones en la orfebrería prerromana". AEspA. 64: 7-21.

NICOLINI, G. (1990): Téchniques des ors antiques. La bijouterie ibérique du VIIe au IVe siècle. Paris.

OLMO, G. Del (1991): "Pervivencias cananeas (ugariticas) en el culto fenicio". Atti del II Congresso Internzionale di Studi Fenici e PuniciI, 367-372. Roma.

OLMOS, R. (1992): "Broncística fenicia y orientalizante en el sur penínsular y en Ibiza". Producciones artesanales fenicio-púnicas. Trabajos del MAI 27; pp.41-64. Ibiza.

OLMOS, R. y FERNÁNDEZ-MIRANDA, M. (1987): "El timiaterio de Albacete". AEspA. LX: 211-219.

PARROT, A.(1970): Asur. Ed. Aguilar. Madrid.

PEREA, A. (1991): Orfebrería prerromana. Arqueología del oro. Madrid.

(1995):"La metalurgia del oro en la fachada atlántica peninsular durante el Bronce Final: interacciones tecnológicas". En M. Ruiz Gálvez (ed.): Ritos de paso y puntos de paso. La Ria de Huelva en el mundo del Bronce Final Europeo. Complutum, extra 5; 69-78. Madrid.

PEREA, A y ARMSBRUSTER, B. (1998): "Cambio tecnológico y contacto entre Atlántico y Mediterráneo: el depósito de "el Carambolo", Sevilla". Trab. Preh ${ }^{a} 55, \mathrm{n}^{\circ} 1$; 121 a 138.

PÉREZ OUTEIRIÑO, B. (1982): De ourivesaria castrexa. I.Arracadas. Boletín avriense 1. Ourense.

ROVIRA, S. (1995): “De metalurgia tartésica”. Tartessos 25 años después (1968-1993), Actas del Congreso Conmemorativo del V Symposium Internacional de Prehistoria Peninsular; pp.475-506. Jerez de la Frontera (Cádiz). 

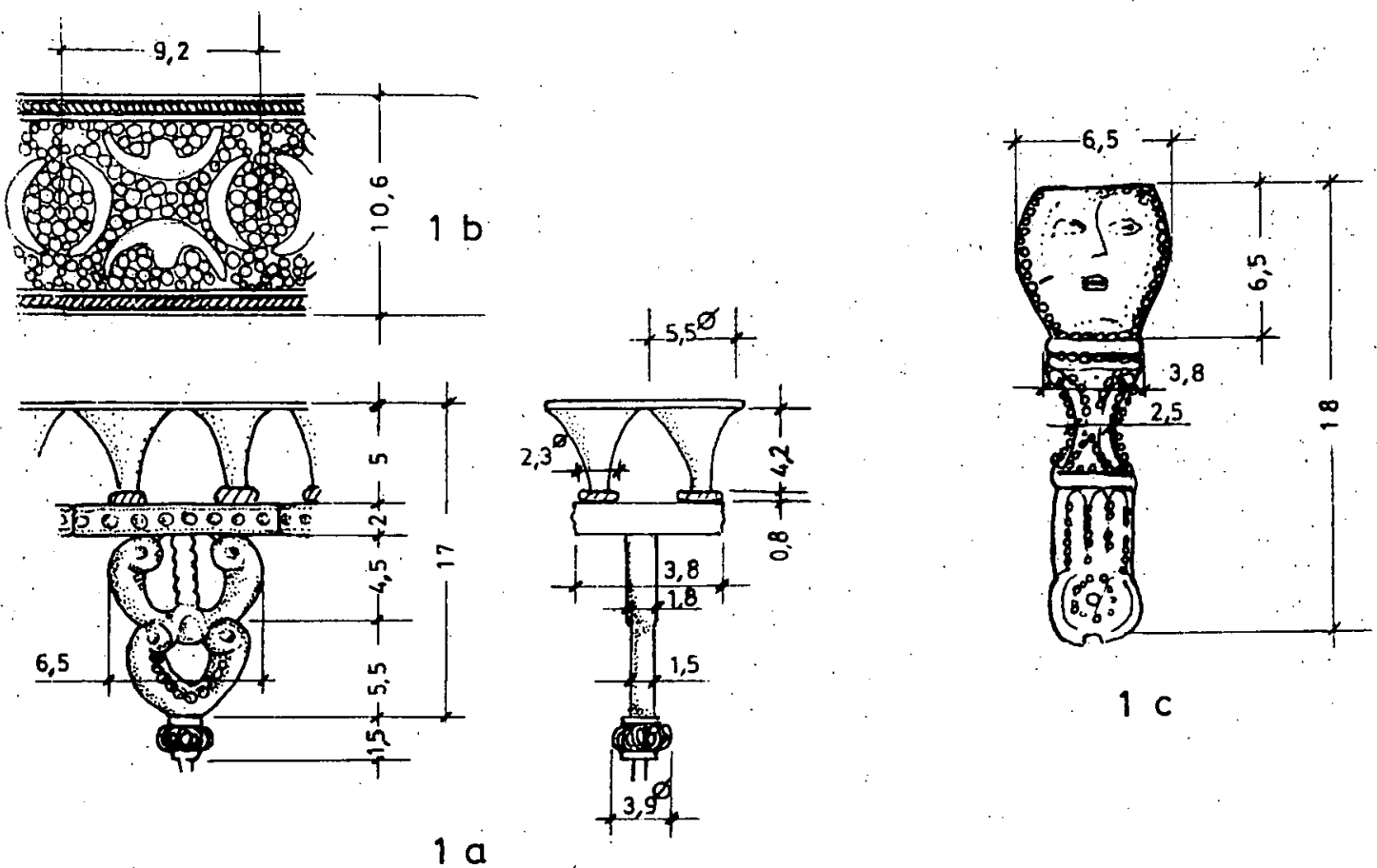

$1 \mathrm{a}$
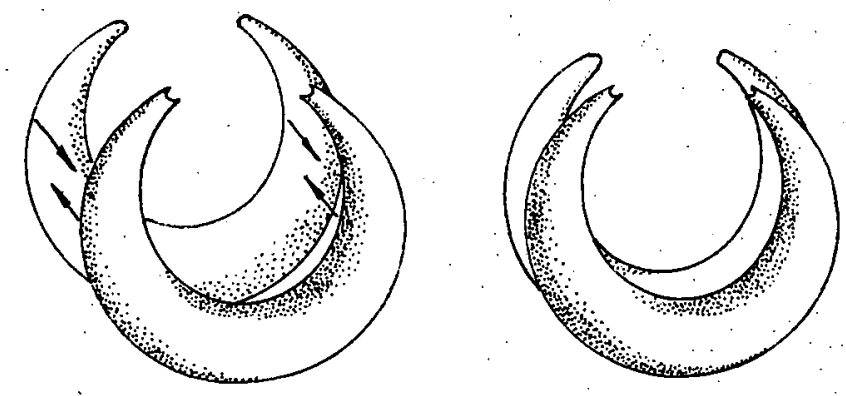

2
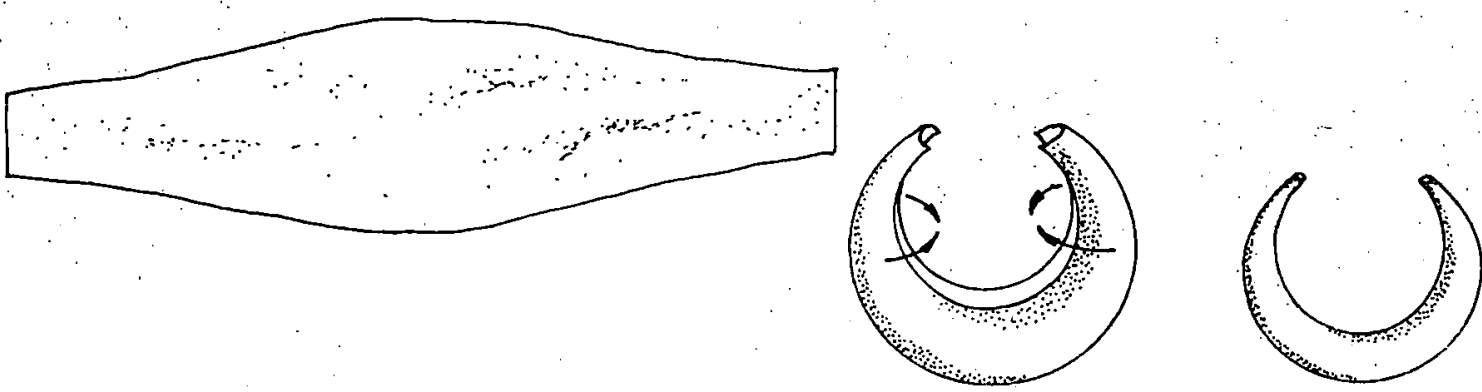

3

Fig. 1: 1a, frente y perfil del grupo floral; $1 \mathrm{~b}$, cara externa de la lámina perimetral. 2 y 3 , dos procesos distintos de elaboración del cuerpo central de la arracada. 


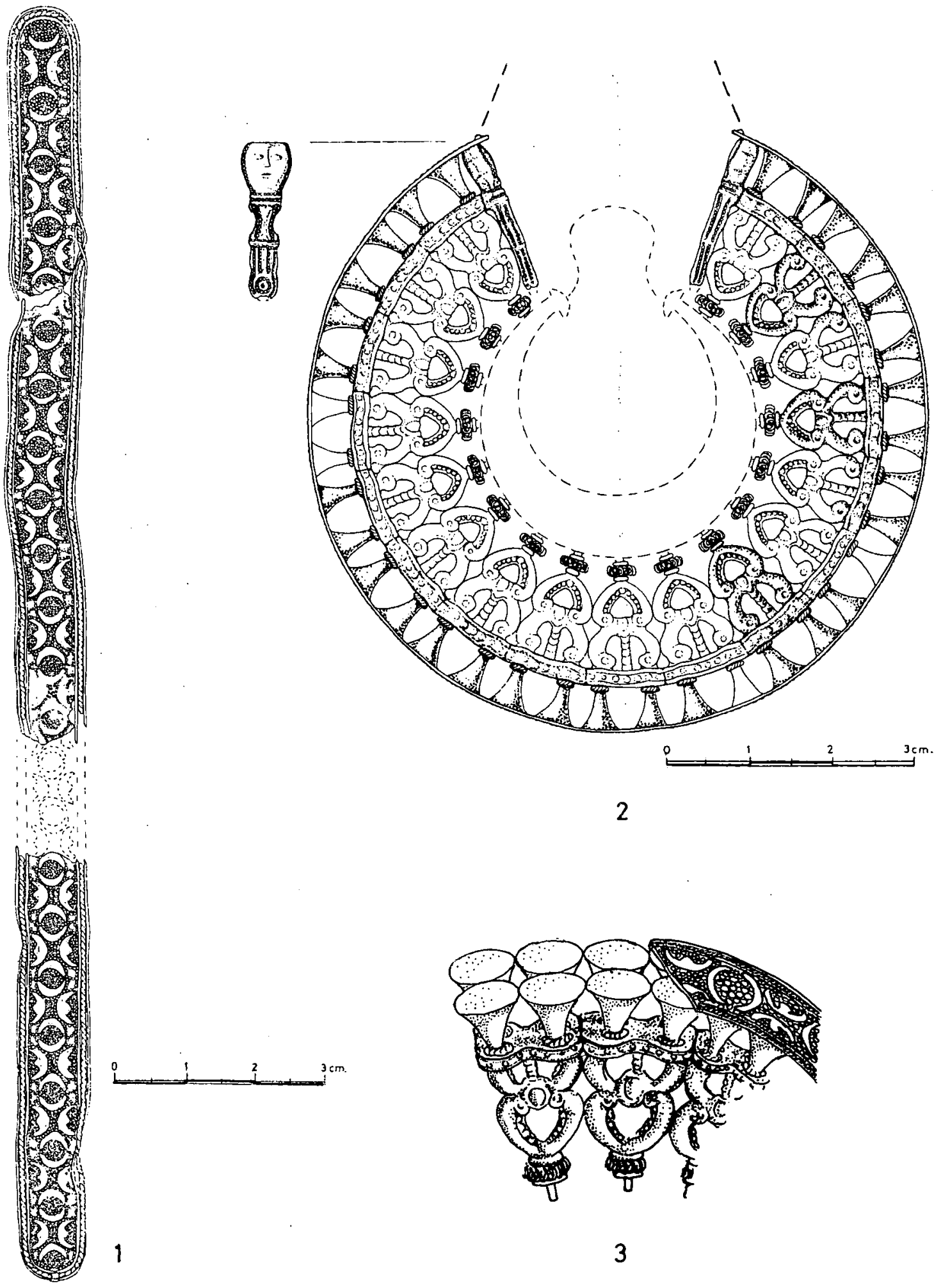

Fig. 2: 1, Desarrollo de la lámina perimetral. 2 y 3, Reconstrucción de la arracada. 


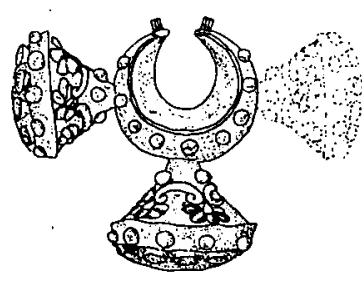

1

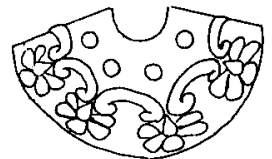

sis

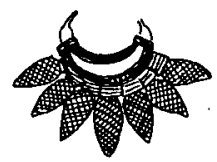

2

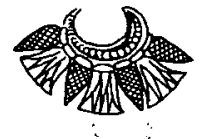

3
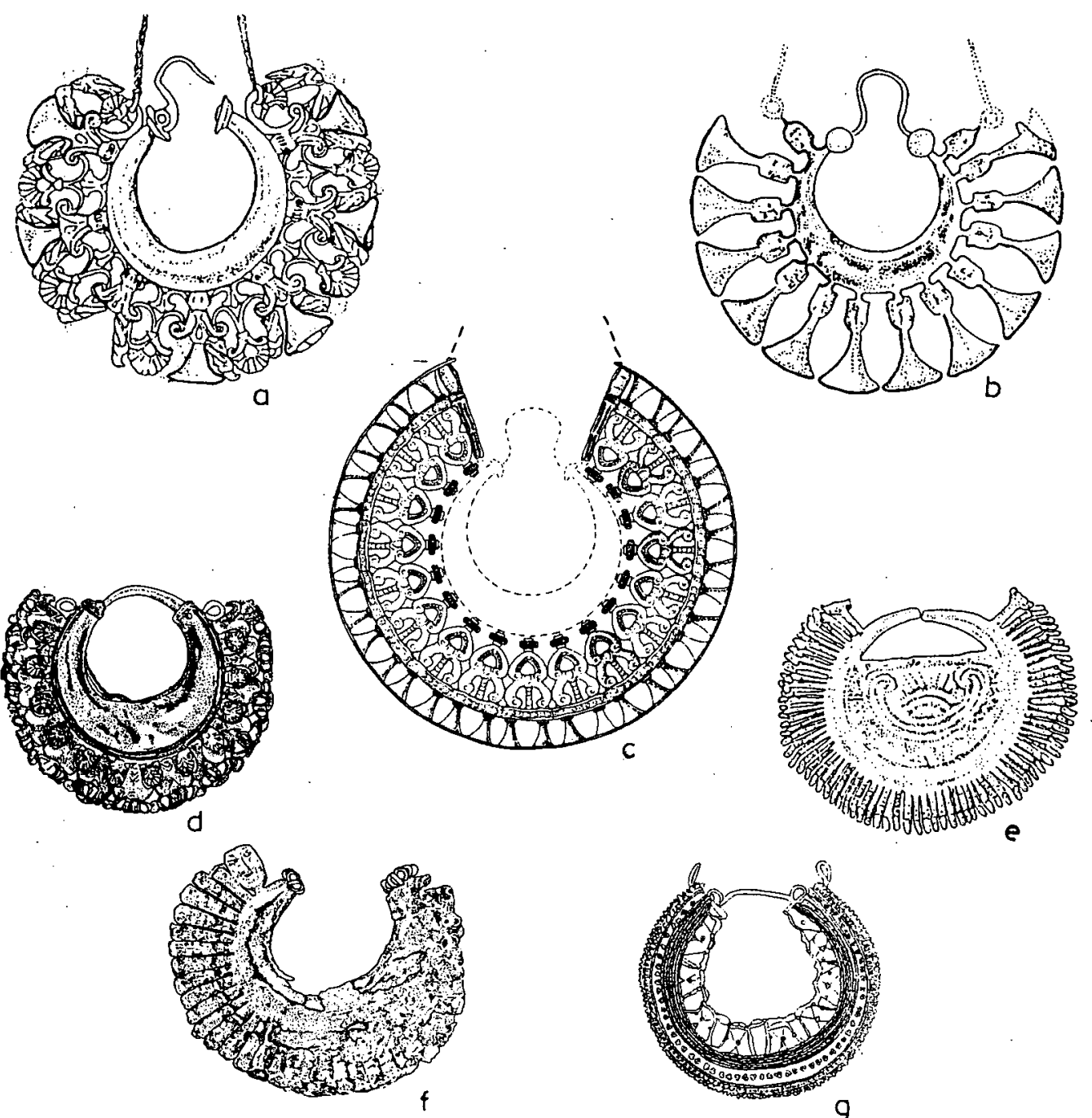

$f$

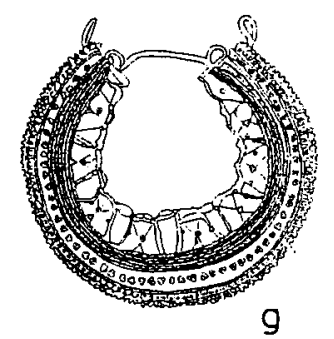

4

Fig. 3: 1, Pendiente de electrum procedente de Van (según Maxwell Hyslop 1971, lám 224, mitad s. VII a.C.). 2 y 3 , Pendientes asirios, tipo 5 de Maxwell Hyslop (fig. 127, 29 y 30). 4, Arracadas peninsulares: a, Aliseda (Cáceres); b, Sines (Gaio; Setubal, Prtubal); c, Villanueva de la Vera (Cáceres); d, Andalucía (antigua colección Vives); e, Baiäo (Porto; Portugal); f, El Pedroso (Sevilla); g, Bedoya, (Pontevedra). 

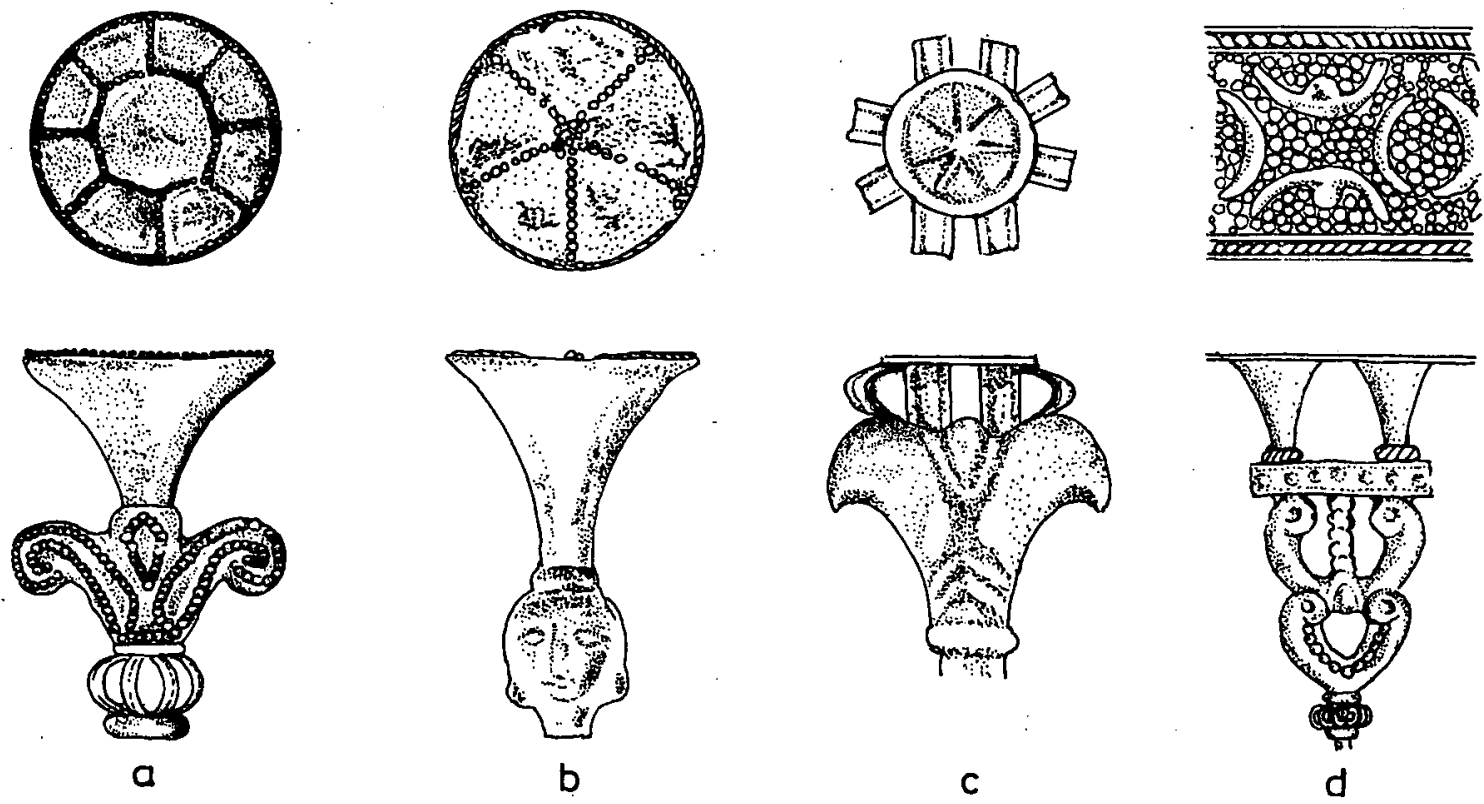

1
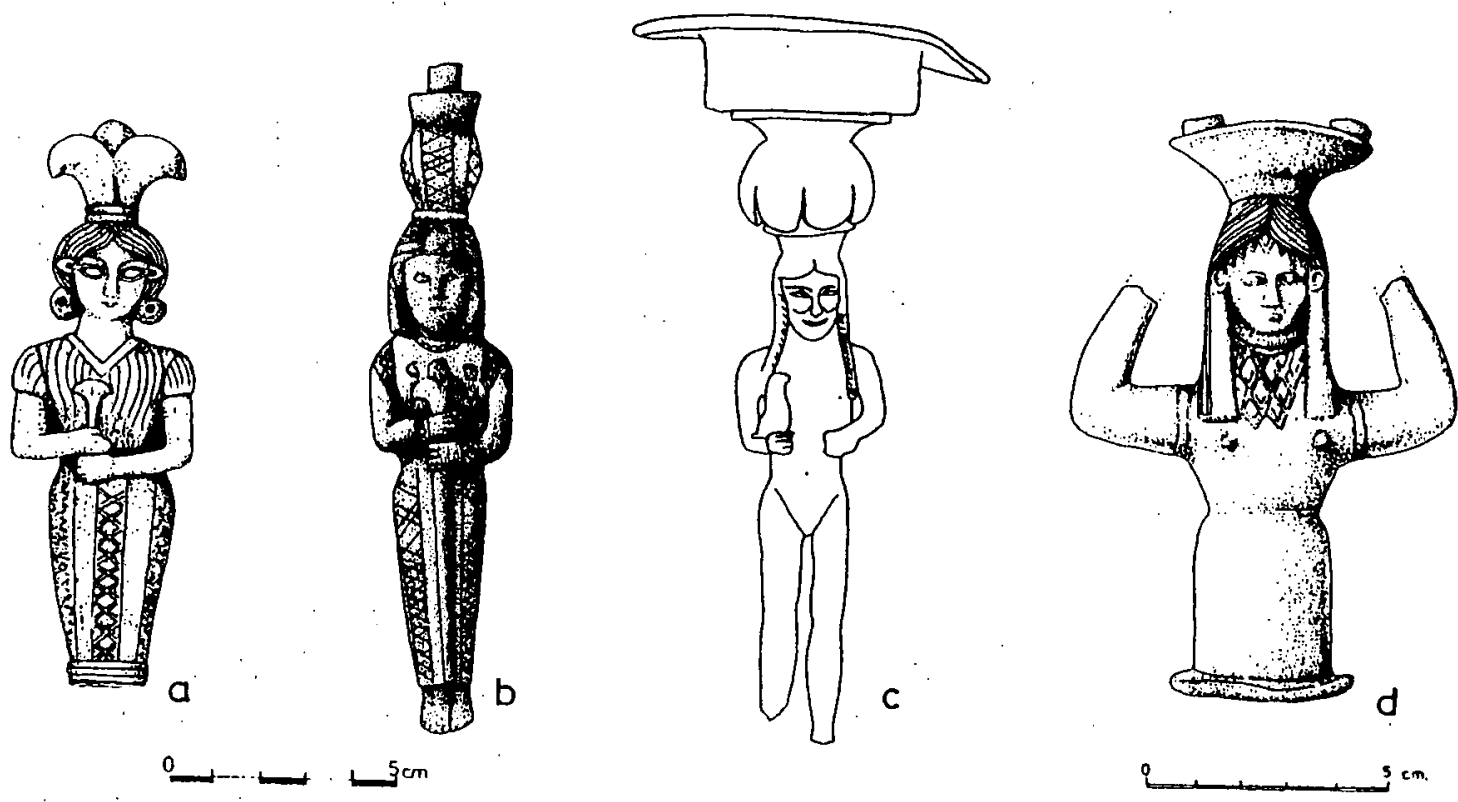

2

Fig. 4: 1, Diferentes motivos en aureolas de arracadas orientalizantes: a, Aliseda; $b$, Sines; $c$, Andalucía; d, Villanueva de Vera. 2, Cariátides de timaterios de bronce orientalizantes: a, Estacar de Robarina (Cástulo, Jaén); b, Villagarcía de la Torre (Badajoz) según Bandera y Ferrer 1994b; c, La Quéjola (San Pedro, Albacete) según Olmos y Fernández 1987; d, El Raso de Candeleda (Ávila) según Fernández Gómez 199). 


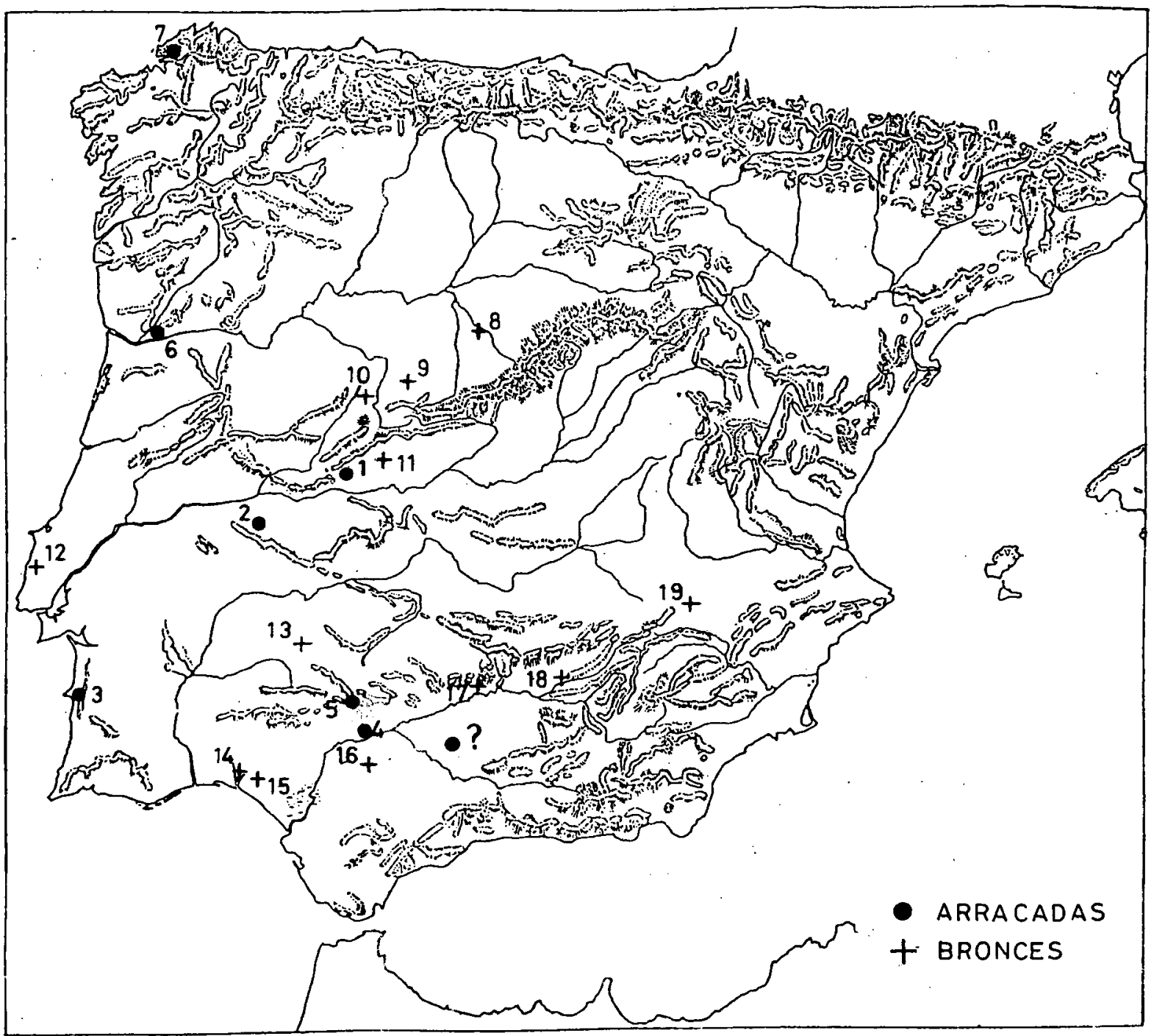

Fig. 5: Dispersión de arracadas orientalizantes Tipo I, y otros objetos de bronces con iconografía y motivos decorativos similares: 1, Villanueva de la Vera. 2, Aliseda. 3, Sines. 4, Setefilla. (¿) Andalucía. 5, El Pedroso. 6, Baiao. 7, Bedoya. 8, Coca. 9, Sanchorreja. 10, El Berrueco. 11, El Raso de Candeleda. 12, Torres Vedras. 13, Villagarcía de la Torre. 14, La Joya (Huelva). 15, Niebla. 16, Carmona. 17, Los Villares (Andújar). 18, Cástulo. 19, La Quéjola (San Pedro). 


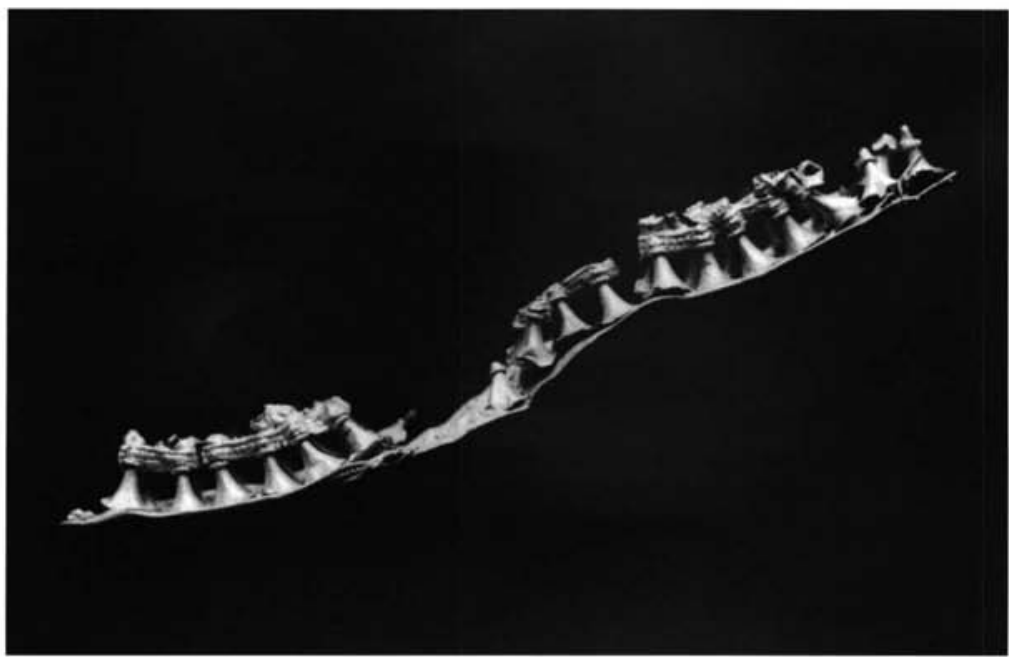

Lám. I. Perfil del fragmento A de la arracada

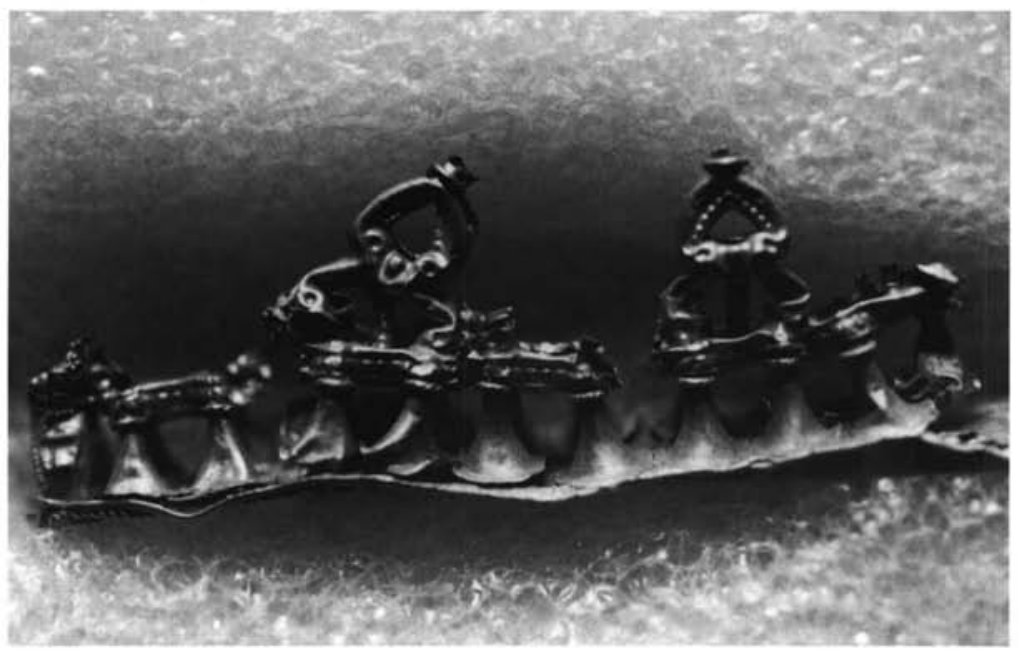

Lám. II. Detalle del fragmento B visto desde el reverso. 


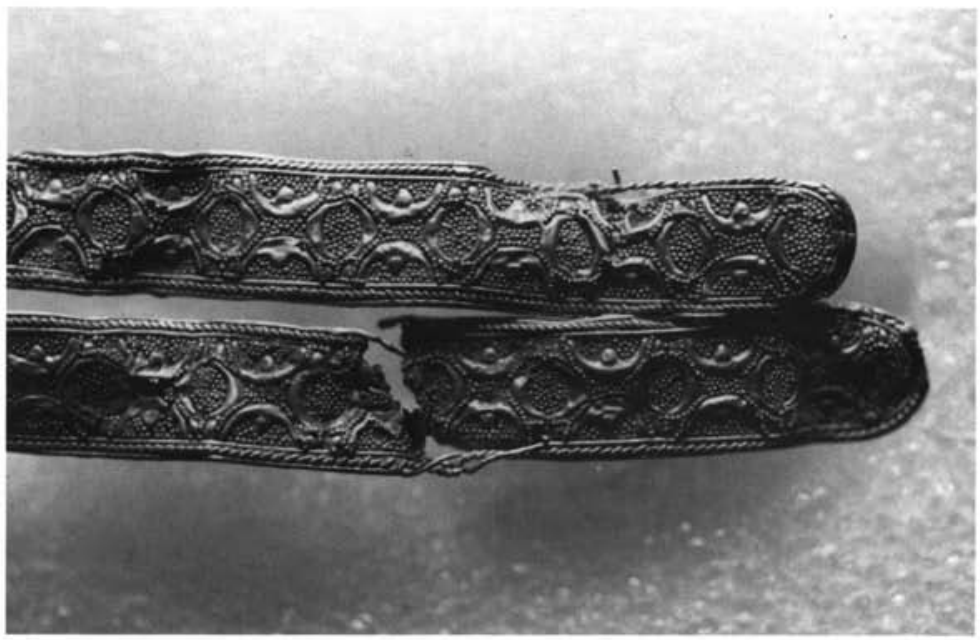

Lám. III. Anverso de las láminas de los dos fragmentos.

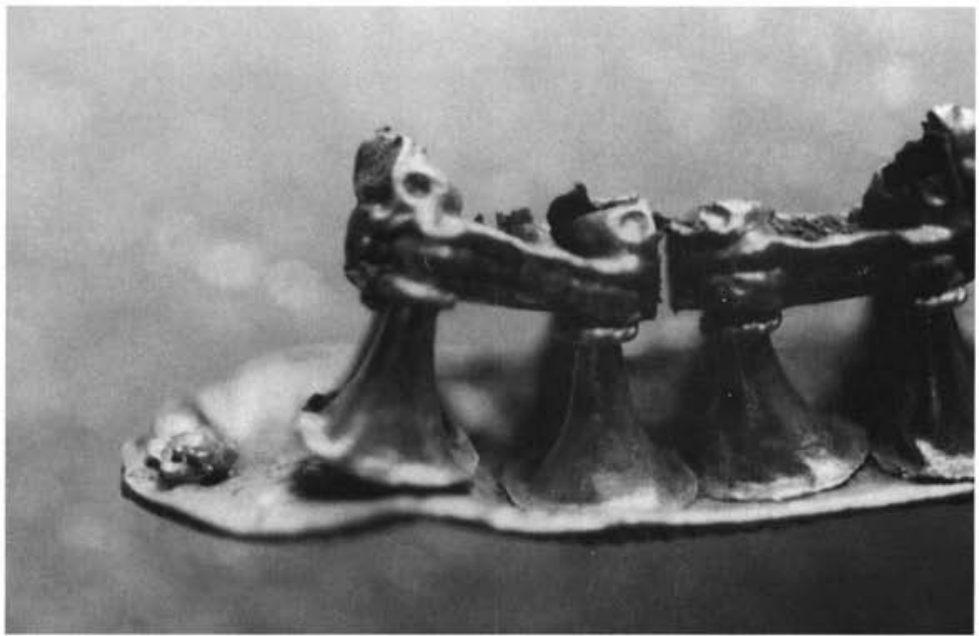

Lám. IV. Fragmento A. Detalle del extremo con grupos de flores y restos del elemento antropomorfo.

ISSN: 1133-4525 ISSN-e: 2255-3924

http://dx.doi.org/10.12795/spal.1998.i7.07 


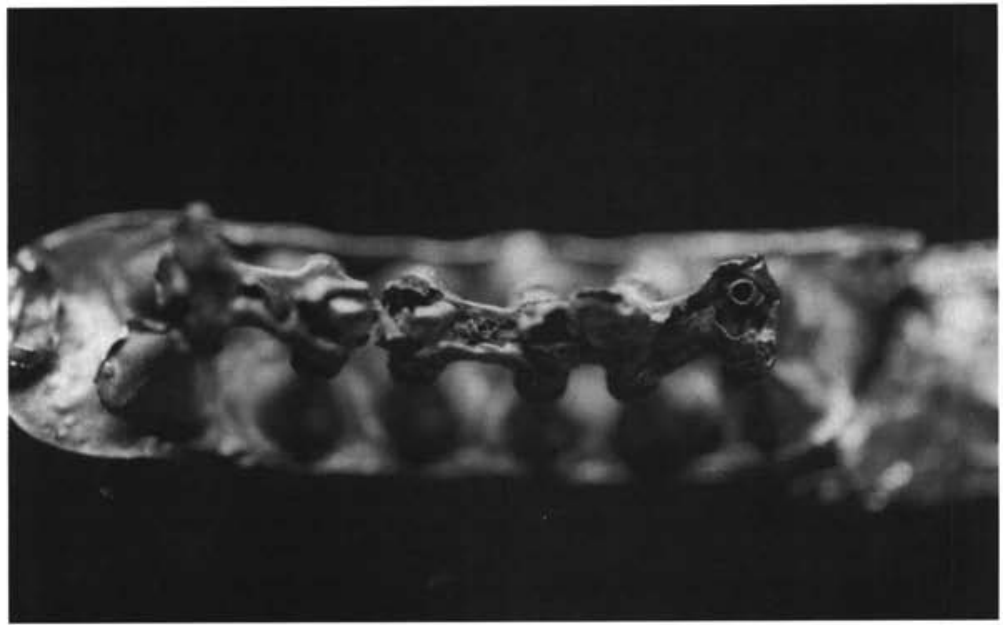

Lám. V. Fragmento A. Detalle de la unión de las flores con la abrazadera.

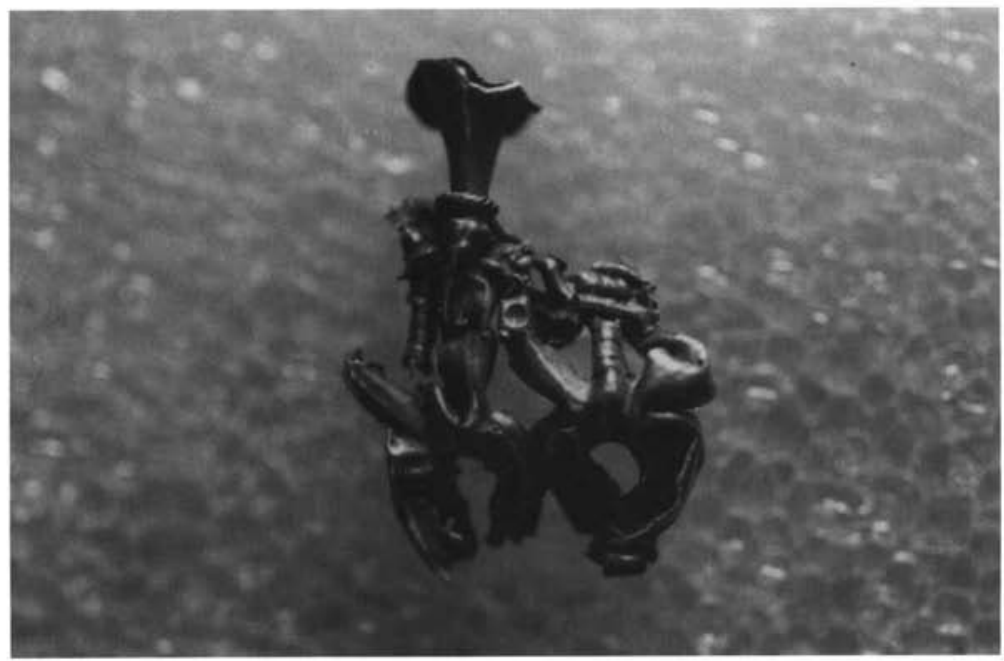

Lám. VI. Pieza suelta. Dos conjuntos aún soldados lateralmente y una flor. 


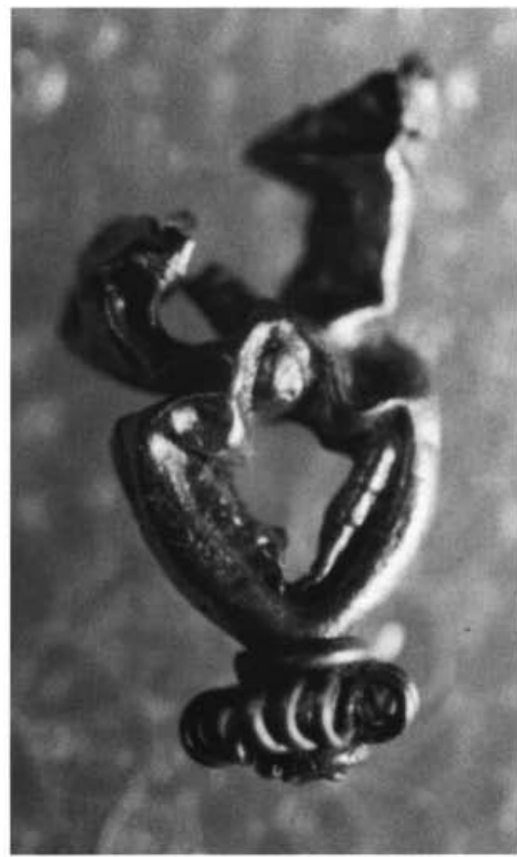

Lám. VIL. Pieza suelta de un conjunto floral que conserva la base con alambre en espiral.

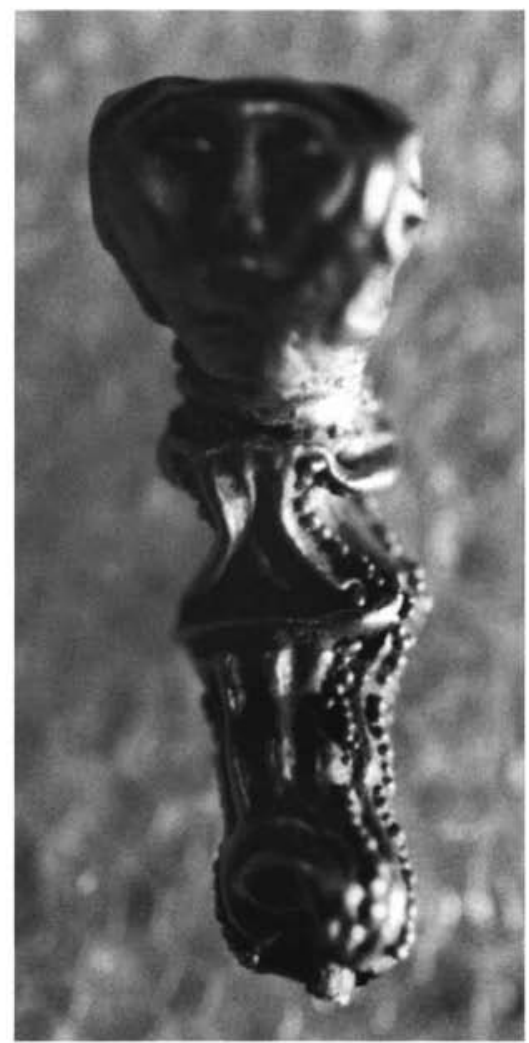

Lám. VIII. Elemento antropomorfo del fragmento A que se conserva desprendido. 